\title{
COMPOSITE DEPTH OF CURE USING FOUR POLYMERIZATION TECHNIQUES
}

\author{
Ericson Janolio de CAMARGO ${ }^{1}$, Eduardo MORESCHI ${ }^{2}$, Wagner BASEGGIO ${ }^{3}$, \\ Jaime Aparecido CURY ${ }^{4}$, Renata Corrêa PASCOTTO5
}

\author{
1- DDS, MSc, Department of Operative Dentistry, Endodontics and Dental Materials, Bauru School of Dentistry, University of São Paulo, Bauru, SP, \\ Brazil. \\ 2- DDS, MSc, Department of Pharmacology, University of Maringa, Maringá, PR, Brazil. \\ 3- DDS, MSc, PhD Student, Department of Operative Dentistry, Endodontics and Dental Materials, Bauru School of Dentistry, University of São \\ Paulo, Bauru, SP, Brazil. \\ 4- DDS, MSc, PhD Professor, Chairman, Area of Biochemistry, Piracicaba Dental School, University of Campinas, Piracicaba, SP, Brazil. \\ 5- DDS, MSc, PhD, Professor, Area of Dentistry, Department of Dentistry, University of Maringa, Maringá, PR, Brazil.
}

Corresponding address: Ericson Janolio de CAMARGO - Rua Bartolomeu de Gusmão 2-55 - apt 409 - Ed Diana - Jardim América - Bauru - SP 17017-336 - e-mail: janolio@usp.com

Received: October 10, 2008 - Modification: February 26, 2009 - Accepted: May 19, 2009

\begin{abstract}
$T_{\mathrm{h}}$ of composite resin restorations. Objective: To evaluate in vitro the effect of four light-curing techniques on depth of cure of a composite resin. Material and Methods: Ten specimens of a composite resin were made in cylindrical cavities prepared in PVC plates $(3.0 \times 7.0 \mathrm{~mm})$ for each light-curing technique. Four photoactivation methods were investigated: stepped, ramped, pulsedelay and traditional. Specimens were longitudinally sectioned and polished for microhardness measurements $\left(\mathrm{kg} / \mathrm{mm}{ }^{2}\right)$, which were made at 0.1, 1.0, 2.0 and $4.0 \mathrm{~mm}$ from the irradiated surface. Data were subjected to ANOVA and Tukey's test. Results: The effect of factors studied (curing method and distance from the surface) and the interaction of these factors was statistically significant $(\mathrm{p}<0.05)$. The traditional method of cure provided higher microhardness values $(69.6 \pm 2.5)$ than the stepped $(63.5 \pm 3.1)$ and pulsed $(63.9 \pm 3.2)$ methods at all depths evaluated, but it did not differ from the ramped method $(66.7 \pm 4.4)$ at 0.1 and $1.0 \mathrm{~mm}$ of depth. Conclusion: All techniques employed provided satisfactory cure of the composite resin up to the depth of $2.0 \mathrm{~mm}$ from the irradiated surface.
\end{abstract}

Key words: Composite resins. Cure. Bisphenol A-Glycidyl Methacrylate.

\section{INTRODUCTION}

Light-cured composite resins have been considered a material of major importance in Restorative Dentistry due to their esthetic properties. However, achievement of clinical and esthetic success with this material involves several aspects, including the curing technique.

The process of curing of composite resins occurs in three main phases: pre-gel, gel point and post-gel. During the pregel phase, the material may flow and undergo molecular rearrangement, in order to compensate shrinkages forces. During this phase, there is a predominance of linear polymer chains. Thereafter, the resin passes from the flow state (pregel) to the viscous state (post-gel), which establishes its gel point. During the post-gel phase, the resin presents a high modulus of elasticity, loses its flowing ability and transmits the stress yielded by polymerization shrinkage to the toothrestoration interface ${ }^{5,15,16}$. At this stage, there is a predominance of cross links in the polymer structure.
Studies have demonstrated that curing technique may influence the polymerization shrinkage of composite ${ }^{3,48-11,15}$. The incomplete curing of composite resins is associated to a reduction in their mechanical properties and biocompatibility, increased content of residual monomers and altered clinical performance due to esthetic impairment, with high tendency to surface staining and possibility of marginal leakage. Therefore, different curing techniques have been suggested to overcome the problems related to polymerization shrinkage, especially postoperative sensitivity and marginal leakage ${ }^{3-7}$.

- Stepped technique (2 stages) - low light intensity is applied for a determined period, followed by high light intensity for a certain additional period.

- Ramped technique (progressive) - initial low light intensity is applied, which is gradually increased for a certain period until it reaches a high final value that s maintained until completion of exposure.

- Pulsed-delay technique (delayed pulse) - initial low 
light intensity is applied for a certain period, which is sufficient to allow curing of the surface. Slow internal polymerization is allowed to occur for 3 to $5 \mathrm{~min}$. Surface finishing and polishing should be performed during this period, followed by a second exposure at a higher light intensity.

The aim of these techniques, which comprise initiation of light-curing at a low light intensity and a delay time, is to allow the occurrence of a more evident pre-gel phase, which would provide a low rate of conversion of monomers and thus allow material flow, yielding low internal stress from shrinkage and providing a good marginal adaptation. At the final stage of these techniques, completion of curing at a high light intensity would provide a proper degree of conversion, which is required for the achievement of satisfactory physical and mechanical properties s,6,7,10,11,18. $^{\text {. }}$

The measurement of microhardness is an indicator of the mechanical, physical and biological properties of a restorative material ${ }^{7}$. The hardness test is an indirect method that indicates the degree of curing ${ }^{1}$. Application of this test in depth as a parameter for analysis of curing is justified, since studies have indicated a good correlation between the Knoop hardness number $\left(\mathrm{KHN}=\mathrm{kg} / \mathrm{mm}^{2}\right)$ and infrared light spectroscopy, a direct method that evaluates the degree of conversion of monomers ${ }^{6}$.

The aim of this study was to evaluate in vitro the effect of four light-curing techniques on the depth of cure of a composite resin by microhardness testing.

\section{MATERIAL AND METHODS}

\section{Experimental Design}

The null hypothesis was that there is no difference between different curing techniques among different depths of cure from the composite resin surface. To test this null hypothesis, a factorial study $4 \times 4$ was conducted and the factors under study were cure technique at 4 levels: Traditional / Continuous (T), Ramped (R), Stepped (S) and Pulse-Delay (PD), and depth of cure at 4 levels 0.1, 1.0, 2.0 and $4.0 \mathrm{~mm}$ from the lighted surface, resulting in 16 groups.

Ten cylindrical specimens were prepared using the composite resin for each condition of cure. The specimens were longitudinally sectioned, polished and microhardness measurements were done at established distances from the surface. Six indentations were made at each distance and the average was obtained.

\section{Specimens Preparation}

Filtek Z250 composite resin (3M/ESPE, St. Paul, MN, USA; shade A2) was used in this study. The specimens were fabricated in cylindrical cavities $(3.0 \mathrm{~mm}$ of diameter $\mathrm{x} 7.0$ $\mathrm{mm}$ of height) prepared in polyvinyl chloride (PVC) plates (Figure 1). Ten specimens were fabricated for each lightcuring method: traditional (continuous), ramped (exponential), stepped (two stages) and pulsed-delay (delayed pulse).

The traditional curing technique was applied with the
Curing Lite 2500 unit (3M/ESPE). The intensity was kept continuous at $600 \mathrm{~mW} / \mathrm{cm}^{2}$ for a constant and continued period of $40 \mathrm{~s}$. The ramped technique is one of the functions of the Optilux 501 unit (Demetron, Kerr, Orange, CA, USA). By this function, the light intensity applied was exponential, reaching $1000 \mathrm{~mW} / \mathrm{cm}^{2}$ during the 10 initial $\mathrm{s}$, followed by additional $10 \mathrm{~s}$ at this intensity. The stepped technique (S) was applied with the VIP unit (Bisco Inc., Schaumburg, IL, USA), similarly to the pulsed-delay technique. The light intensity employed for this technique was followed by two stages, being the first at low intensity and the last at a high light intensity. The values of this intensity were $200 \mathrm{~mW} /$ $\mathrm{cm}^{2}$ for $10 \mathrm{~s}$ and $600 \mathrm{~mW} / \mathrm{cm}^{2}$ for $30 \mathrm{~s}$, respectively. The pulsed-delay technique comprised treatment at high and low light intensities with a time interval. It was applied with the VIP unit (Bisco Inc.). The intensities applied were $100 \mathrm{~mW} /$ $\mathrm{cm}^{2}$ for $5 \mathrm{~s}$, followed by a time interval of $3 \mathrm{~min}$ and a final light-curing at $600 \mathrm{~mW} / \mathrm{cm}^{2}$ for $30 \mathrm{~s}$.

After curing, the PVC plates were longitudinally sectioned throughout the specimens with diamond discs (Diamond wafering blade, 15HC \# 11-4244; Buehler Ltd., Lake Bluff, IL, USA) coupled in a saw (Isomet low speed saw; Buehler Ltd.). Both halves of each specimen were fixed in an acrylic disc with stick wax. The cut surfaces of the specimens were finished and polished in a polishing machine (Arotec APL 4; Arotec Ind. Com., São Paulo, SP, Brazil), with serial silicon carbide papers of decreasing abrasiveness (grits 320, 400, 600 and 1200) and felt $(6 \mu \mathrm{m}, 3 \mu \mathrm{m}, 1 \mu \mathrm{m})$ with a diamond suspension (Buehler Metadi; Buehler Ltd.) with grits corresponding to felts. The specimens were stored under moist conditions at $\pm 37^{\circ} \mathrm{C}$ for $24 \mathrm{~h}$ before the microhardness determination.

\section{Microhardness Measurement}

Depth of cure was determined by a microhardness tester (Future Tech with software FM-ARS) with a $25 \mathrm{~g}$ load for 5 $\mathrm{s}$. This device provided the Knopp hardness $\left(\mathrm{kg} / \mathrm{mm}^{2}\right)$. For each half of specimen was made three indentations, resulting in six indentations per specimen. They were made at the depths of $0.1,1.0,2.0$ and $4.0 \mathrm{~mm}$ from the surface where the polymerization was made (Figure 1). The six indentations were averaged ( $\mathrm{n}=10$ for each depth). The ratio of hardness at $1.0,2.0$ and $4.0 \mathrm{~mm}$ from the surface related to the value at $0.1 \mathrm{~mm}$ was calculated and the value $\geq 0.80(80 \%)$ is considered acceptable.

\section{Statistical Analysis}

The variables under study were cure technique at 4 levels and depth in the specimen at 4 levels with 10 repetitions, resulting in a sample number of $4 \times 4 \times 10$.

Data were subjected to two-way ANOVA at the significance level of 5\%, for observation of the relationship between microhardness, depth and interaction between the light-curing methods investigated, followed by Tukey test. The SAS program (version 8.02, SAS Institute Inc., Cary, $\mathrm{NC}$, USA) was used for the analysis and the significance level set at $5 \%$. 


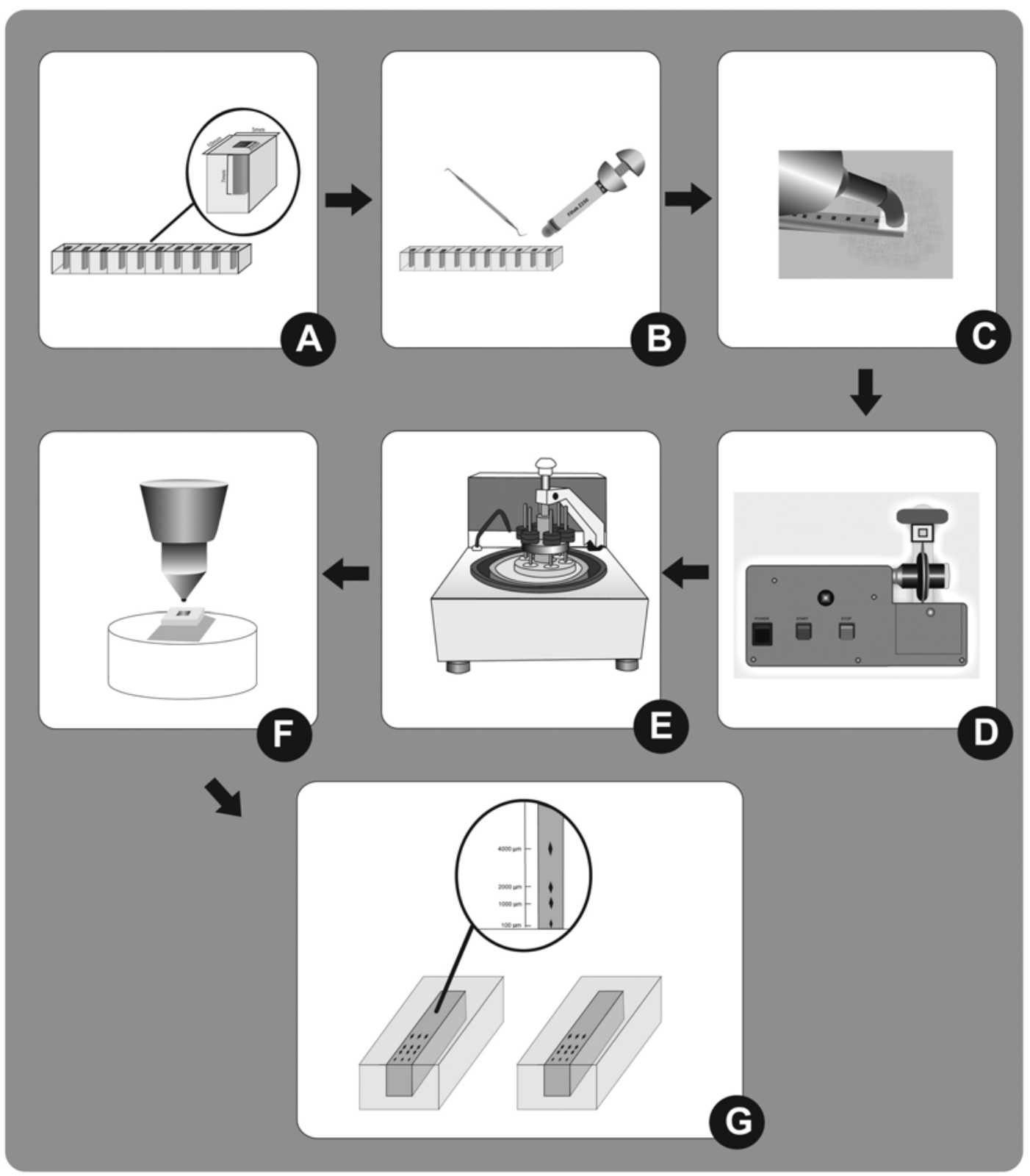

FIGURE 1- Schematic representation of experimental phase. a) Polyvinyl chloride (PVC) plates with cylindrical cavities (3.0 $\mathrm{mm} \times 7.0 \mathrm{~mm}$ ) prepared to do the specimens; b) Insertion of composite resin in the plates. c) Curing methods; d) Sectioning of the specimen in the central region. e) Finishing and polishing of the specimen surface; f) Microhardness tester; g) Schematic illustration of the polyvinyl chloride (PVC) plates, showing the microhardness indentations at different depths from the surface of the composite specimens

\section{RESULTS}

Knoop microhardness mean values recorded for the specimens using the four study methods, as well as the standard deviation and percent curing in relation to the most superficial region are presented in Table 1. Up to the depth of $2.0 \mathrm{~mm}$, all curing techniques showed an acceptable relative hardness compared to the $0.1 \mathrm{~mm}$ value $(\geq 0.80)$ (Table 1).

There was a statistically significant effect for the interaction method of cure distance from the surface and for the isolated factors $(p<0.05)$. For all depths of cure, the traditional method provided higher Knoop microhardness values compared to the new light-curing methods, stepped and pulsed $(p<0.05)$. The ramped method was similar to the traditional method at depths of 0.1 and $1.0 \mathrm{~mm}(\mathrm{p}>0.05)$ but lower values at the deepest depth $(p<0.05)$. The microhardness values decreased according to the distance from the external surface $(\mathrm{p}<0.05)$, irrespective of the curing method used. 
TABLE 1- Knoop microhardness $\left(\mathrm{Kg} / \mathrm{mm}^{2}\right)$ means ( \pm standard deviation; $\left.\mathrm{n}=10\right)$ of the specimens according to the curing methods and depth $(\mathrm{mm})$ from the external irradiated surface

\begin{tabular}{|c|c|c|c|c|}
\hline \multirow{2}{*}{$\begin{array}{l}\text { Depth } \\
(\mathrm{mm})\end{array}$} & \multirow[b]{2}{*}{ Traditional } & \multicolumn{2}{|c|}{ Curing methods } & \multirow[b]{2}{*}{ Stepped } \\
\hline & & Ramped & Pulsed-delay & \\
\hline 0.1 & $73.5 \pm 3.3 \mathrm{Aa}$ & $71.7 \pm 6.0 \mathrm{Aab}$ & $68.2 \pm 3.7 \mathrm{Ab}$ & $67.7 \pm 3.2 \mathrm{Ab}$ \\
\hline 1.0 & $69.3 \pm 2.4 \mathrm{Ba}[0.94]^{*}$ & $66.6 \pm 3.4 \mathrm{Bab}[0.93]^{*}$ & $63.2 \pm 3.2 \mathrm{Bb}[0.93]^{*}$ & $63.0 \pm 3.3 \mathrm{Bb}[0.93]^{*}$ \\
\hline 2.0 & $66.0 \pm 1.9 \mathrm{Ca}[0.90]^{*}$ & $61.9 \pm 3.8 \mathrm{Cb}[0.86]^{*}$ & $60.4 \pm 2.8 \mathrm{Cb}[0.88]^{*}$ & $59.8 \pm 2.9 \mathrm{Cb}[0.88]^{*}$ \\
\hline 4.0 & $58.8 \pm 2.6 \mathrm{Da}[0.80]^{*}$ & $48.7 \pm 4.7 \mathrm{Db}[0.68]^{*}$ & $51.5 \pm 3.1 \mathrm{Db}[0.77]^{*}$ & $50.9 \pm 3.0 \mathrm{Db}[0.75]^{*}$ \\
\hline
\end{tabular}

Different letters indicate statistically significant differences $(p<0.05)$; uppercase letters compare the effect of depth of cure for each curing method (within columns) and lowercase letters compare curing methods for each depth of cure (within lanes). *[Microhardness ratio relative to the $0.1 \mathrm{~mm}$ value]

\section{DISCUSSION}

Ideally, the degree of curing should be the same throughout the depth of the restoration, and the ratio of hardness (more external / more internal) should be equal to 1 or a close value. When a composite resin increment is cured, light passes through its interior and loses intensity due to dispersion, leading to a lower curing effectiveness ${ }^{14}$. This light dispersion inside the bulk of material leads to the difference in microhardness between the external and internal surfaces. Light-curing of composite resins is considered adequate when this proportion is equal to or higher than $80 \%(\mathrm{n}=0.80)^{7,14}$. With regard to the mean Knoop microhardness values in depth and the methods evaluated, the ratio of curing was higher than that reported by those authors up to the depth of $2.0 \mathrm{~mm}$ (Table 1). These data confirm the recommendation that resin increments should be limited to a maximum thickness of $2.0 \mathrm{~mm}$ for achievement of satisfactory curing $g^{3,4,6,7,10,14,15}$.

Concerning the effectiveness of curing of the new modulated techniques, the results of the present study indicated that they are favorable for curing, as demonstrated by the Knoop microhardness test, when these techniques were applied using the same curing times, intensities and materials investigated, according to other studies ${ }^{3,4,7,15-18}$.

Regarding the new light-curing techniques, the ramped method was able to cure $2.0 \mathrm{~mm}$ of composite resin in a shorter time $(20 \mathrm{~s})$, even at a lower light density, when compared to the traditional method. Satisfactory microhardness values were obtained with this technique in the present study. Considering that the higher the degree of conversion, the higher the microhardness, the present outcomes confirm those of Bouschlicher, et al. ${ }^{3}$. Similarly to the present microhardness values for the ramped and traditional techniques up to $2 \mathrm{~mm}$ in depth, those authors found a similar degree of conversion between these two methods, which was able to reduce the conversion rate up to $1 \mathrm{~mm}$ below the most external surface by the ramped method. However, this did not significantly affect the total conversion of the material with use of both methods. Initially, the lower conversion rate with the ramped method allowed a reduction in the stress rate and maximum shrinkage stress, with no damage to the physical properties of the restorative material ${ }^{6,12,13,15,17}$. Other studies investigated the forces yielded during polymerization shrinkage and demonstrated that the pre-gel phase is extremely fast in composite resins cured by high light intensities as used in conventional continuous $\left(600 \mathrm{~mW} / \mathrm{cm}^{2}-40 \mathrm{~s}\right)$, which therefore is a negative aspect of this technique ${ }^{8,10,12,17}$.

The microhardness values achieved by the stepped and pulsed methods were lower than those obtained with the traditional method. Despite the numerical difference between groups as seen in Table 1, those methods provided satisfactory curing, as demonstrated by De Wald, et al. ${ }^{7}$. and Rueggeberg, et al. ${ }^{14}$. In order to validate the mechanical behavior of a composite resin and, probably from a clinical point of view, it could not be consider as an isolated element to affect the behavior of the restoration. With regard to the stepped technique, the results found by Bouschlincher, et al. ${ }^{2}$, comprising comparison of the force intensity and maximum shrinkage force, did not demonstrate any difference between the traditional and stepped methods.

Despite the initial low light intensity, curing techniques may give rise to reduce polymerization shrinkage due to stress relief by allowing flow to occur during setting ${ }^{3,4,8}$, some material's chemical and physical properties could be negatively affected, producing a polymer mechanically more fragile. A recent study ${ }^{2}$ found that low power density applied to the composite resin at the initial periods of polymerization reaction resulted in polymers with increased susceptibility to softening in ethanol, in spite of achieving a comparable degree of cure to that of the conventional continuous technique. It has been hypothesized that slow start polymerization are probably associated with relatively few centers of polymer growth, generating a small number of free radicals, resulting in a more linear polymeric structure, with lower cross linking density, as evidenced by reduced glass transition temperature and increased susceptibility to ethanol degradation ${ }^{2}$.

Although the pulsed technique yielded lower microhardness values than those achieved by the traditional method, due to the lower light density, the material also 
presented an acceptable degree of curing $(n=0.80)^{7,14}$. The outcomes of other studies ${ }^{7,10,14-18}$ corroborate this finding, with the report that initial low light intensity does not lead to a considerable decrease in the mechanical properties. Moreover, specific literature has demonstrated that lightcuring techniques comprising initial low light intensity provided better marginal sealing than those that use high light intensity ${ }^{1-6,9-12}$.

This study evaluated microhardness in depth. Further clinical and laboratory studies on the force and shrinkage vectors and the gaps yielded by the characteristic inherent to this material should be conducted, in order to determine the real performance of curing techniques in relation to shrinkage and performance of composite resin restorations in a long-term basis.

\section{CONCLUSIONS}

It may be concluded that: 1 . Composite resin curing by the 4 light curing methods provided decreasing means of microhardness in relation to the surface, according to the increase in depths analyzed; 2 . At the depth corresponding to the resin increment recommended by the manufacturer $(2.0 \mathrm{~mm})$, all curing techniques provided satisfactory composite hardness; 3 . The use of initial low light intensity for curing composite resins does not compromise the microhardness up to $2.0 \mathrm{~mm}$ depth.

\section{ACKNOWLEDGMENTS}

The authors acknowledge CNPq for financial support (Grant \# 0178/2003 - Book 001).

\section{REFERENCES}

1- Asmussen E. Composite restorative resins: composition versus wallto-wall polymerization contraction. Acta Odontol Scand. 1975;33(6):33744.

2- Asmussen E, Peutzfeldt A. Influence of pulse-delay curing on softening of polymer structures. J Dent Res. 2001;80(6):1570-3.

3- Bouschlicher MR, Rueggeberg FA. Effect of ramped light intensity on polymerization force and conversion in a photoactivated composite. J Esthet Dent. 2000;12(6):328-39.

4- Bouschlicher MR, Rueggeberg FA. Effect of stepped light intensity on polymerization force and conversion in a photoactivated composite. J Esthet Dent. 2000;12(1):23-32.

5- Davidson CL, Feilzer AJ. Polymerization shrinkage and polymerization shrinkage stress in polymer-based restorations. J Dent. 1997;25(6):43540

6- Davidson CL, De Gee AJ. Relaxation of polymerization contraction stresses by flow in dental composites. J Dent Res. 1984;63(2):146-8.

7- De Wald JP, Ferracane JL. A comparison of four modes of evaluating depth of cure of light-cured restorative materials. J Prosthet Dent. 1987;66(3):727-30.
8- Feilzer AJ, De Gee AJ, Davidson CL. Setting stress in composite resin for two different curing modes. Dent Mater. 1993;9(1):2-5.

9- Feilzer AJ, Dooren LH, De Gee AJ, Davidson CL. Influence of light intensity on polymerization shrinkage and integrity of restoration-cavity interface. Eur J Oral Sci. 1995;103(5):322-6.

10- Kanca J 3rd, Suh BI. Pulse activation: reducing resin-based composite contraction stresses at the enamel cavosurface margins. Am J Dent. 1999;12(3):107-12.

11- Lim BS, Ferracane JL, Sakaguchi RL, Condon JR. Reduction of polymerization contraction stress for dental composites by two-step light activation. Dent Mater. 2002;18(6):436-44.

12- Kinomoto Y, Torri M. Photoelastic analysis of polymerization contraction stresses in resin composite restorations. J Dent. 1998;26(2):165-71

13- Ferracane JL. Elution of leachable components from composites. J Oral Rehabil.1994;21(4):441-52.

14- Rueggeberg FA, Caughman WF, Curtis JW, Davis HC. Factors affecting cure at depths within light-activated resin composites. Am J Dent. 1993;6(2):91-5.

15- Sakaguchi RL, Berge HX. Reduced light energy density decreases post-gel contraction while maintaining degree of conversion in composites. J Dent. 1998;26(8):695-700.

16- Soh MS, Yap AUJ. Influence of curing modes on crosslink density in polymer structures. J Dent. 2004;32(4):321-6.

17- Yap AUJ, Soh MS, Siow KS. Post gel shrinkage with pulse activation and soft-start polymerization. Oper Dent. 2002;27(1):81-7.

18- Witzel MF, Calheiros FC, Gonçalves F, Wawano Y, Braga RR. Influence of photoactivation method on conversion, mechanical properties, degradation in ethanol and contraction of resin-based materials. J Dent. 2005;33(9):773-9. 